\title{
Germinação e vigor de sementes de Bauhinia divaricata $L$.
}

\author{
Germination and vigor of the Bauhinia divaricata $L$. seeds
}

\author{
Edna Ursulino Alves ${ }^{\mathrm{I}, *}$ Carlos Demetrius Lima do Nascimento ${ }^{\mathrm{II}}$ \\ Riselane de Lucena Alcântara Bruno ${ }^{I}$ Anarlete Ursulino Alves ${ }^{\text {III }}$ Joel Martins Braga Júnior ${ }^{\text {II }}$ \\ Edson de Almeida Cardoso ${ }^{\text {II }}$ Evio Alves GalindoII Kelina Bernardo Silva ${ }^{\text {III }}$
}

\section{RESUMO}

A pata-de-vaca (Bauhinia divaricata) é uma espécie arbórea, amplamente distribuída no Brasil, de alto valor ornamental e econômico. Sua propagação ocorre por meio de sementes, cuja germinação tem sido pouco investigada. Dessa forma, o presente trabalho teve como objetivo definir o tipo de substrato e a temperatura mais adequados para avaliar a germinação e o vigor de sementes de Bauhinia divaricata. $O$ experimento foi realizado no Laboratório de Análise de Sementes do CCA-UFPB, em Areia-PB, em delineamento inteiramente casualizado com os tratamentos distribuídos em esquema fatorial $3 \times 5$, com os fatores temperaturas constantes de 25 e $30^{\circ} \mathrm{C}$ e alternada $20-30^{\circ} \mathrm{C}$ e substratos entre papel, sobre papel, rolo de papel, entre areia e entre vermiculita, em quatro repetições de 25 sementes, em câmaras tipo BOD, com fotoperíodo de oito horas. Foram analisadas as seguintes variáveis: porcentagem de germinação, primeira contagem $e$ índice de velocidade de germinação e massa seca de plântulas. Concluiu-se que a temperatura de $25^{\circ} \mathrm{C}$, juntamente com os substratos entre papel, sobre papel e rolo de papel, é adequada para condução de testes de germinação e vigor com sementes de Bauhinia divaricata. O substrato areia nas três temperaturas (20-30, 25 e $30^{\circ} \mathrm{C}$ ) foi responsável pelas menores porcentagens de germinação e níveis de vigor das sementes.

Palavras-chave: pata de vaca, sementes florestais, planta medicinal.

\section{ABSTRACT}

The Bauhinia divaricata is an arboreal species with high ornamental and economical value and distributed throughout Brazil. It is propagated by seeds, from which germination needs more investigation. So, this study was carried out at the Seed Analysis Laboratory pertaining to CCA-UFPB

\begin{abstract}
- Areia, in BOD-type chambers with 8 h photoperiod in order to determine the most adequate substratum and temperature for evaluating the germination and vigor of the Bauhinia divaricata seeds. The entirely randomized experimental design in the factorial scheme $3 \times 5$ was used. The factors were constituted by constant temperatures of 25 and $30^{\circ} \mathrm{C}$ and alternate $20-30^{\circ} \mathrm{C}$, as well as substrata between paper, on paper, paper roll, among sand and among vermiculite, in four replicates of 25 seeds. The following variables were analyzed: percent germination, first counting, germination index and dry matter of the plantlets. The $25^{\circ} \mathrm{C}$ temperature and the substrata between paper, on paper and paper roll showed to be adequate to the test for germination and vigor of the Bauhinia divaricata seeds. The lowest germination percentages and the seed vigor levels occurred in the sand substratum at three temperatures (20-30, 25 and $30^{\circ} \mathrm{C}$ ).
\end{abstract}

Key words: cow paw, forest seeds, medicinal plant.

\section{INTRODUÇÃO}

A pata de vaca (Bauhinia divaricata), mais conhecida como pata de vaca, unha de boi, entre outros, é uma espécie nativa do Sul do Brasil, do Paraguai, da Argentina e do Uruguai, com ocorrência nos bordos das matas, podendo ser encontrada na forma de arbusto ou árvore com até seis metros de altura. Suas folhas são utilizadas nas inflamações renais, como diuréticas, hipoglicemiantes e hipocolesteremiantes, sendo considerada uma planta medicinal de uso popular (LORENZI, 2002).

IDepartamento de Fitotecnia, Centro de Ciência Agrárias (CCA), Universidade Federal da Paraíba (UFPB), CP 02, 58397-000, Areia, PB, Brasil. E-mail: edanaursulino@cca.ufpb.br.*Autor para correspondência.

${ }^{\mathrm{II}} \mathrm{CCA} / \mathrm{UFPB}$, Areia, PB, Brasil.

II'Programa de Pós-graduação em Agronomia, CCA/UFPB, Areia, PB, Brasil. 
Atualmente, existe uma grande preocupação por parte dos pesquisadores e analistas de sementes, sobretudo dos que trabalham com espécies florestais, em conduzir estudos que forneçam informações sobre a qualidade das sementes, especialmente no que diz respeito à padronização, agilização, aperfeiçoamento e estabelecimento dos métodos de análise. Nas Regras para Análise de Sementes (BRASIL, 1992), existem prescrições para a condução do teste de germinação de um grande número de espécies cultivadas; no entanto, as espécies florestais nativas ainda são pouco pesquisadas.

O substrato é o suporte onde se condicionam as sementes para germinar, cuja função é manter as condições adequadas para germinação e desenvolvimento das plântulas (PIÑA-RODRIGUES \& VIEIRA, 1988; FIGLIOLIA et al., 1993). Os tipos mais utilizados, descritos e prescritos em BRASIL (1992) são: pano, papel toalha, papel de filtro, papel mata-borrão, terra vegetal e areia, devendo estar adequadamente úmidos para que forneçam às sementes a quantidade de água necessária à germinação. Para sementes de espécies florestais, muitos substratos têm sido testados, tais como carvão, esfagnum, vermiculita, papel toalha, papel de filtro, papel mata-borrão, terra vegetal, areia, entre outros (ALBUQUERQUE et al., 1998).

Para sementes de Peltophorum dubium (Spreng) Taubert, PEREZ et al. (1999) indicaram o papelfiltro como o mais adequado para condução de testes de germinação. Enquanto BEZERRA et al. (2002) relataram que os substratos areia, solo e Plugmix ${ }^{\circledR}$ foram os mais indicados para a germinação de sementes de Momordica charantia L. Também MACHADO et al. (2002) relataram que, nas condições ideais de temperatura, os substratos areia e papel são promissores para uso no teste de germinação de sementes de Tabebuia serratifolia (Vahl) Nicholson.

A temperatura influi no processo de germinação, especialmente por alterar a velocidade de absorção de água e modificar a velocidade das reações químicas que irão acionar o desdobramento, o transporte das reservas e a ressíntese de substâncias para a plântula (CARVALHO \& NAKAGAWA, 2000). De acordo com BORGES \& RENA (1993), as sementes de diferentes espécies apresentam faixas distintas de temperatura para a germinação, considerando-se como ótima a temperatura na qual a mais alta porcentagem de germinação é obtida, no mais curto espaço de tempo, sendo a mínima e a máxima, respectivamente, a mais baixa e a mais alta temperatura na qual a germinação não ocorre.
De forma geral, a temperatura máxima para a germinação de muitas sementes encontra-se entre $35 \mathrm{e}$ $40^{\circ} \mathrm{C}$ e a ótima entre 15 e $30^{\circ} \mathrm{C}$ (COPELAND \& MAcDONALD, 1995). No entanto, BORGES \& RENA (1993) observaram que a faixa de 20 a $30^{\circ} \mathrm{C}$ tem se mostrado como adequada para a germinação das sementes de espécies tropicais e subtropicais e, para ALBRECHT et al. (1986), a temperatura mais adequada para a germinação das sementes da maioria das espécies encontra-se entre 26,5 e $35^{\circ} \mathrm{C}$. CAVALCANTE \& PEREZ (1995) estudaram o efeito da temperatura na germinação de sementes de Leucaena leucocephala (Lam.) de Wit e verificaram que a faixa de máxima germinação foi de 20 a $35^{\circ} \mathrm{C}$. Dentro desta faixa, determinaram $30^{\circ} \mathrm{C}$ como sendo a temperatura ótima de germinação e 10 e $45^{\circ} \mathrm{C}$, os extremos mínimo e máximo, respectivamente.

Outro fator importante a ser ressaltado é a interação entre temperatura e substrato, na qual a capacidade de retenção de água e a quantidade de luz que o substrato permite chegar à semente podem ser responsáveis por diferentes respostas obtidas até para uma mesma temperatura (FIGLIOLIA et al., 1993). Nesse sentido, RAMOS \& VARELA (2003) enfatizaram que as respostas encontradas para as interações entre substratos e temperaturas das sementes de Parkia discolor Benth. evidenciam que a germinação total pode ser maximizada com a correta utilização do substrato adequado para determinada temperatura e da temperatura adequada para determinado substrato.

O substrato sobre papel, à temperatura constante de $30^{\circ} \mathrm{C}$, foi recomendado para condução de testes de germinação e vigor em sementes de Ocotea corymbosa (Meissn.) Mez (BILIA et al., 1998); entre vermiculita, a $20-30$ ou $25^{\circ} \mathrm{C}$ para Euterpe edulis Mart (ANDRADE et al., 1999) e sobre areia, a $30^{\circ} \mathrm{C}$, em Acosmium nitens (Vog.) Yakovlev (VARELA et al., 2005).

Diante da importância do gênero Bauhinia na medicina popular, bem como da carência de estudos referentes à propagação da espécie via sementes, a presente pesquisa teve como objetivo definir o tipo de substrato e a temperatura ideal para auxiliar na condução de testes de germinação e vigor em sementes de Bauhinia divaricata.

\section{MATERIAL E MÉTODOS}

O trabalho foi realizado no Laboratório de Análise de Sementes do Departamento de Fitotecnia do Centro de Ciências Agrárias da Universidade Federal da Paraíba (CCA-UFPB), em Areia - PB, entre julho e setembro de 2004. As sementes utilizadas de Bauhinia divaricata foram colhidas manualmente de 10 árvores 
no município de Areia-PB. Logo após a colheita, os frutos foram colocados para secar ao sol por um período de cinco dias, para facilitar a abertura das vagens e, conseqüentemente, a obtenção das sementes.

O teste de germinação, para todos os substratos, foi conduzido em germinadores regulados para temperaturas constantes de 25 e $30^{\circ} \mathrm{C}$, bem como para alternada de $20-30^{\circ} \mathrm{C}$. As sementes foram semeadas nos substratos papel (sobre, entre e rolo de papel), areia e vermiculita, sob fotoperíodo de oito horas. Para os substratos areia e vermiculita, as sementes foram semeadas em bandejas plásticas perfuradas no fundo, com dimensões de $50 \times 30 \times 5 \mathrm{~cm}$, entre os referidos substratos, previamente esterilizados em autoclave e umedecidos com quantidade de água equivalente a $60 \%$ da capacidade de retenção.

Para os substratos entre e sobre papel, os testes foram instalados em caixas plásticas transparentes de 11 x 11 x 3cm, com tampa, tipo gerbox, nas quais as sementes foram semeadas sobre duas folhas de papel mata-borrão e, para o substrato entre papel, cobertas com pedaços de papel germitest. No substrato rolo de papel, as sementes foram distribuídas sobre duas folhas de papel germitest e cobertas com uma terceira. Em seguida, os papéis foram confeccionados em forma de rolo e levados para o germinador. O papel foi previamente esterilizado e umedecido com água destilada, na proporção de 2,5 vezes o seu peso seco. Os efeitos dos tratamentos foram avaliados por meio dos testes de germinação e vigor descritos a seguir.

Germinação - foram utilizadas quatro repetições de 25 sementes por tratamento, cujas contagens do número de sementes germinadas iniciaram-se aos sete e se estenderam até os 20 dias após a semeadura, utilizando como critério as plântulas normais (BRASIL, 1992); primeira contagem de germinação - contagem das plântulas normais no $12^{\circ}$ dia após o início do teste; índice de velocidade de germinação (IVG) - realizadas contagens diárias dos 12 aos 20 dias, das plântulas normais e o índice calculado conforme a fórmula proposta por MAGUIRE (1962); comprimento de plântulas - vinte dias após a semeadura, as plântulas normais foram retiradas das bandejas e medidas com o auxílio de uma régua graduada em centímetros; massa seca de plântulas - logo após as medições, as plântulas normais foram postas para secar em estufa regulada a $80^{\circ} \mathrm{C}$ por 24 horas e, decorrido esse período, pesadas em balança analítica (NAKAGAWA, 1999).

O experimento foi instalado em delineamento inteiramente ao acaso, com os tratamentos distribuídos em esquema fatorial $3 \times 5$, onde o primeiro fator representou as temperaturas $\left(20-30,25\right.$ e $\left.30^{\circ} \mathrm{C}\right)$ e o segundo, os substratos (sobre e entre papel, rolo de papel, entre areia e vermiculita). Os dados foram submetidos à análise da variância, utilizando-se o teste F para comparação dos quadrados médios e as médias comparadas pelo teste de Tukey, a 5\% de probabilidade de erro. Nas análises estatísticas, utilizou-se o software ESTAT, versão 2.0/2001.

\section{RESULTADOS E DISCUSSÃO}

De acordo com os dados da tabela 1, observou-se que, com exceção do substrato areia, na temperatura de $25^{\circ} \mathrm{C}$, foram registradas as maiores porcentagens de germinação, com destaque para o substrato entre papel, enquanto que as menores porcentagens de germinação ocorreram na temperatura alternada de $20-30^{\circ} \mathrm{C}$, exceto no substrato entre papel. Dessa forma, constata-se que, na temperatura de $25^{\circ} \mathrm{C}$, as sementes encontraram as condições propícias para expressar o seu máximo potencial germinativo, enquanto que, na temperatura de $20-30^{\circ} \mathrm{C}$, ocorreu o inverso, ou seja, não favoreceu a germinação, ao contrário, constituiu-se em obstáculo a ser vencido pelas sementes para conseguirem germinar. Resultados diferentes foram obtidos por VARELA et al. (2005) com Acosmium nitens, onde o substrato papel de filtro mostrou-se prejudicial à germinação de suas sementes.

A temperatura ótima para a germinação de sementes está diretamente associada às características ecológicas da espécie (PROBERT, 1992). Nas temperaturas constantes, obtiveram-se porcentagem e velocidade maiores de germinação das sementes, em comparação com as temperaturas alternadas. O fato de ocorrer germinação em ambos os regimes de temperatura indica que as sementes dessa espécie são capazes de germinar em pequenas clareiras, evidenciando uma adaptação às flutuações térmicas naturais do ambiente. No entanto, preferem condições de sub-bosque, nas quais predominam amplitudes térmicas menores. Essas características conferem à $\boldsymbol{B}$. divaricata capacidade maior de estabelecimento das plântulas em campo, tornando-as capazes de suportar as condições adversas do ambiente.

Os resultados obtidos no presente trabalho estão de acordo com COPELAND \& MACDONALD (1995), quando relataram que a temperatura ótima para a germinação de muitas sementes encontrava-se entre 15 e $30^{\circ} \mathrm{C}$. Também MARCOS FILHO (1986) e BORGES \& RENA (1993) observaram que a faixa de 20 a $30^{\circ} \mathrm{C}$ se mostrou adequada para a germinação das sementes de espécies tropicais e subtropicais, enquanto CETNARSKI FILHO \& NOGUEIRA(2005) e SILVA et 
Tabela 1 - Germinação e primeira contagem de germinação de sementes de Bauhinia divaricata, em função de diferentes substratos e temperaturas. CCA-UFPB, Areia, 2004.

\begin{tabular}{|c|c|c|c|c|}
\hline \multirow[t]{2}{*}{ Substratos } & \multicolumn{4}{|c|}{ 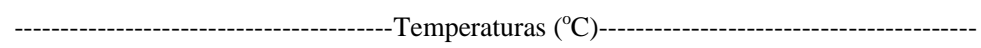 } \\
\hline & $20-30$ & 25 & 30 & Média \\
\hline Sobre papel & $95 \mathrm{aA}$ & $98 \mathrm{abA}$ & $94 \mathrm{aA}$ & $96 \mathrm{a}$ \\
\hline Entre papel & 85 bC & $100 \mathrm{aA}$ & $94 \mathrm{aB}$ & 93 a \\
\hline Rolo de papel & $85 \mathrm{bB}$ & $98 \mathrm{abA}$ & 93 aA & 92 a \\
\hline Areia & $9 \mathrm{dC}$ & 17 cB & $25 \mathrm{cA}$ & $17 \mathrm{c}$ \\
\hline Vermiculita & 39 сC & $92 \mathrm{bA}$ & $73 \mathrm{bB}$ & $68 \mathrm{~b}$ \\
\hline Média & $63 \mathrm{C}$ & $81 \mathrm{~A}$ & $76 \mathrm{~B}$ & \\
\hline CV (\%) & \multicolumn{4}{|c|}{10,77} \\
\hline \multirow[t]{2}{*}{ Substratos } & \multicolumn{4}{|c|}{ } \\
\hline & $20-30$ & 25 & 30 & Média \\
\hline Sobre papel & $59 \mathrm{aC}$ & $98 \mathrm{abA}$ & $87 \mathrm{aB}$ & 81 a \\
\hline Entre papel & $52 \mathrm{aC}$ & $100 \mathrm{aA}$ & $89 \mathrm{aB}$ & 80 a \\
\hline Rolo de papel & $35 \mathrm{bC}$ & $98 \mathrm{abA}$ & $90 \mathrm{aB}$ & $74 \mathrm{~b}$ \\
\hline Areia & $9 \mathrm{~dB}$ & 20 cA & $11 \mathrm{cB}$ & $13 \mathrm{~d}$ \\
\hline Vermiculita & 20 cC & $91 \mathrm{bA}$ & $29 \mathrm{bB}$ & $47 \mathrm{c}$ \\
\hline Média & $35 \mathrm{C}$ & $81 \mathrm{~A}$ & $61 \mathrm{~B}$ & \\
\hline CV (\%) & \multicolumn{4}{|c|}{7,43} \\
\hline
\end{tabular}

Médias não seguidas da mesma letra, minúscula na coluna e maiúscula na linha, diferem estatisticamente entre si pelo teste de Tukey a 5\% de significância.

al. (2006) estudaram o efeito da temperatura na germinação de sementes de Ocotea odorifera (Vellozo) Rohwer e Oenocarpus minor Mart., respectivamente, e verificaram que a faixa de máxima germinação situouse entre 25 e $30^{\circ} \mathrm{C}$.

Para a germinação de sementes de Genipa americana, ANDRADE et al. (2000) recomendaram as temperaturas constantes de 25,30 e $35^{\circ} \mathrm{C}$, juntamente com os substratos vermiculita e solo. Também MACHADO et al. (2002) constataram que a faixa ótima de temperatura para germinação de sementes de Tabebuia serratifolia situou-se entre 25 e $35^{\circ} \mathrm{C}$, enquanto IOSSI et al. (2003) verificaram que as temperaturas de 25 e $30^{\circ} \mathrm{C}$ resultaram em maior porcentagem de germinação, independentemente do substrato utilizado (vermiculita, serragem, areia e esfagno).

Estudos realizados por SILVA \& AGUIAR (2004) com sementes de Cnidosculus phyllacanthus indicaram que as maiores porcentagens de germinação ocorreram na temperatura alternada de $20-30^{\circ} \mathrm{C}$, independentemente do substrato utilizado (papel germitest, areia, vermiculita e papel de filtro), enquanto que, para sementes de Myracrodruon urundeuva Fr. All., PACHECO et al. (2006) verificaram que as temperaturas de 25 e $27^{\circ} \mathrm{C}$ proporcionaram às sementes resultados satisfatórios de germinação e vigor em todos os substratos testados, com exceção do substrato entre papel a $27^{\circ} \mathrm{C}$.

À semelhança do que ocorreu para a porcentagem de germinação, para os dados da primeira contagem, os maiores valores também ocorreram na temperatura constante de $25^{\circ} \mathrm{C}$, em todos os substratos. As menores porcentagens de germinação, na primeira contagem, ocorreram na temperatura alternada de 20$30^{\circ} \mathrm{C}$, independentemente do substrato (Tabela 1). NAKAGAWA (1999) comentou que o teste de primeira contagem, muitas vezes, expressa melhor o vigor do que o índice de velocidade de germinação. Assim, constatou-se que, na presente pesquisa, o referido teste confirmou os resultados da porcentagem de germinação, em que, na temperatura de $25^{\circ} \mathrm{C}$, obtiveramse os melhores resultados. Mais uma vez, observa-se que, na temperatura de $25^{\circ} \mathrm{C}$, foi possível às sementes demonstrarem seu potencial fisiológico máximo.

O substrato rolo de papel à temperatura de $30^{\circ} \mathrm{C}$ constante também foi recomendado para condução de testes de germinação e vigor em sementes de Cedrela odorata (ANDRADE \& PEREIRA, 1994). De forma semelhante, o substrato rolo de papel, juntamente com a temperatura constante de $35^{\circ} \mathrm{C}$, 
proporcionaram os melhores valores de germinação na primeira contagem de sementes de Acacia mangium (LIMA \& GARCIA, 1996).

As maiores porcentagens de germinação de sementes de Mimosa caesalpiniifolia, por ocasião da primeira contagem, ocorreram com o substrato entre papel nas quatro temperaturas $\left(20,20-30,25\right.$ e $\left.30^{\circ} \mathrm{C}\right)$ utilizadas no substrato sobre papel a 20 e $25^{\circ} \mathrm{C}$ constantes, não diferindo do substrato entre areia, a $25^{\circ} \mathrm{C}$ constantes (ALVES et al., 2002).

Em relação aos valores médios do índice de velocidade de germinação (Tabela 2), verificou-se que, na temperatura de $25^{\circ} \mathrm{C}$ foram registrados os melhores resultados, enquanto que, naquela de $20-30^{\circ} \mathrm{C}$, mais uma vez, ocorreram os menores índices de velocidade de germinação em todos os substratos. Também SILVA \& AGUIAR (2004) constataram que, para o teste de vigor, velocidade de germinação de sementes de Cnidosculus phyllacanthus, o melhor substrato foi o papel de filtro combinado com as temperaturas alternadas de $20-30^{\circ} \mathrm{C}$. No entanto, VARELA et al. (2005) verificaram que, no substrato sobre papel, nas temperaturas de 30 e $35^{\circ} \mathrm{C}$, não ocorreu germinação das sementes de Acosmium nitens.

A temperatura responsável pelas maiores porcentagem e velocidade de germinação foi igual, discordando das observações de CARVALHO \& NAKAGAWA (2000) e MARCOS FILHO (2005), os quais relataram que a temperatura ótima para velocidade de germinação é sempre um pouco mais alta do que para o total de germinação. Dessa forma, observa-se, que na temperatura de $25^{\circ} \mathrm{C}$, as sementes conseguiram expressar se máximo potencial germinativo e nível de vigor, provavelmente pelo fato de ser esta a temperatura ideal para condução de testes de germinação e vigor com sementes de $\boldsymbol{B}$. divaricata.

Em sementes de Euterpe edulis, os maiores valores para o índice de velocidade de germinação foram obtidos na temperatura de $20-30$ alternada e $25^{\circ} \mathrm{C}$ constante, juntamente com o substrato entre vermiculita (ANDRADE et al., 1999). Os maiores índices de velocidade de germinação de sementes de Mimosa caesalpiniifolia foram registrados com o substrato entre papel, independentemente da temperatura (20, 20-30, 25 e $30^{\circ} \mathrm{C}$ ) e, no substrato sobre papel, a $25^{\circ} \mathrm{C}$ constantes (ALVES et al., 2002). Em contrapartida, os substratos papel e areia (entre e sobre), nas temperaturas de 20 e $30^{\circ} \mathrm{C}$ constantes, proporcionaram os menores índices de velocidade de germinação em sementes de Muntingia calabura L. (LOPES et al., 2002). Já para Phoenix roebelenii, o maior índice de velocidade de germinação foi obtido na temperatura

Tabela 2 - Índice de velocidade de germinação (IVG) de sementes e massa seca de plântulas de Bauhinia divaricata, oriundas de sementes, em função de diferentes substratos e temperaturas. CCA-UFPB, Areia, 2004.

\begin{tabular}{|c|c|c|c|c|}
\hline Substratos & $20-30$ & 25 & 30 & Média \\
\hline Sobre papel & $3,81 \mathrm{aC}$ & 5,85 aA & $4,46 \mathrm{aB}$ & $4,71 \mathrm{a}$ \\
\hline Entre papel & $3,70 \mathrm{aC}$ & $6,24 \mathrm{aA}$ & $4,40 \mathrm{aB}$ & $4,78 \mathrm{a}$ \\
\hline Rolo de papel & $3,37 \mathrm{aC}$ & 6,00 aA & $4,30 \mathrm{aB}$ & $4,56 \mathrm{a}$ \\
\hline Areia & $0,33 \mathrm{cB}$ & $0,71 \mathrm{cAB}$ & $1,11 \mathrm{cA}$ & $0,72 \mathrm{c}$ \\
\hline Vermiculita & $1,29 \mathrm{bC}$ & $3,75 \mathrm{bA}$ & $2,70 \mathrm{bB}$ & $2,58 \mathrm{~b}$ \\
\hline Média & $2,50 \mathrm{C}$ & 4,51 A & 3,39 B & \\
\hline \multirow[t]{2}{*}{ CV (\%) } & \multicolumn{4}{|c|}{7,36} \\
\hline & ------------- & ---Massa se & §/plântula)- & --------- \\
\hline Substratos & $20-30$ & 25 & 30 & Média \\
\hline Sobre papel & $0,260 \mathrm{abC}$ & $0,463 \mathrm{aB}$ & $0,691 \mathrm{aA}$ & $0,471 \mathrm{a}$ \\
\hline Entre papel & $0,311 \mathrm{aB}$ & $0,405 \mathrm{aB}$ & $0,831 \mathrm{aA}$ & $0,515 \mathrm{a}$ \\
\hline Rolo de papel & 0,062 bA & 0,101 bA & 0,192 bA & $0,118 \mathrm{~b}$ \\
\hline Areia & $0,318 \mathrm{aC}$ & $0,527 \mathrm{aB}$ & 0,797 aA & $0,547 \mathrm{a}$ \\
\hline Vermiculita & $0,262 \mathrm{abB}$ & $0,371 \mathrm{aB}$ & $0,752 \mathrm{aA}$ & $0,462 \mathrm{a}$ \\
\hline Média & $0,243 \mathrm{C}$ & 0, 373 B & 0,653 A & \\
\hline CV (\%) & & & & \\
\hline
\end{tabular}

Médias não seguidas da mesma letra, minúscula na coluna e maiúscula na linha, diferem estatisticamente entre si pelo teste de Tukey a 5\% de significância.

Ciência Rural, v.38, n.4, jul, 2008. 
constante de $30^{\circ} \mathrm{C}$, com o esfagno ou a areia, enquanto na vermiculita ocorreu o menor valor (IOSSI et al., 2003).

De acordo com os dados da tabela 2, verificou-se que os maiores valores de massa seca das plântulas foram obtidos na temperatura de $30^{\circ} \mathrm{C}$, independentemente do substrato utilizado. De um modo geral, a temperatura alternada de $20-30^{\circ} \mathrm{C}$, independentemente do substrato adotado, foi a responsável pelos menores valores de massa seca das plântulas. Nas temperaturas mais elevadas, a exemplo daquela de $30^{\circ} \mathrm{C}$, as atividades metabólicas ocorrem de maneira mais rápida e eficiente; por isso, o maior conteúdo de massa seca das plântulas oriundas de sementes submetidas à referida temperatura deve-se, provavelmente, a uma maior rapidez e eficiência na translocação das reservas degradadas nas fases iniciais da germinação. Segundo CARVALHO \& NAKAGAWA (2000), o processo germinativo compreende uma seqüência extremamente complexa de reações bioquímicas, pelas quais substâncias armazenadas no tecido de sustentação são desdobradas, transportadas e ressintetizadas no eixo embrionário, de maneira que a germinação será mais rápida e o processo mais eficiente quanto maior for a temperatura, até certo limite.

Ao estudar a qualidade fisiológica de sementes de Mimosa caesalpiniifolia, ALVES et al. (2002) constataram que o substrato entre papel proporcionou os maiores valores de massa seca a $20^{\circ} \mathrm{C}$, enquanto a $25^{\circ} \mathrm{C}$ não houve diferença entre os substratos e, a $20-30$ e $30^{\circ} \mathrm{C}$, destacaram-se os substratos entre papel e entre areia. Nas pesquisas de SANTOS et al. (1994), o substrato areia foi responsável pelo maior valor do peso seco da parte aérea e das raízes de plântulas de Mimosa caesalpiniaefolia. GARCIA (1994) constatou que as temperaturas de 30 ou $35^{\circ} \mathrm{C}$ proporcionaram maior peso seco dos cotilédones nas plântulas de Theobroma grandiflorum. Enquanto isso, IOSSI et al. (2003) obtiveram os menores valores para a massa seca da parte aérea e do sistema radicular de plântulas de Phoenix roebelenii com o substrato vermiculita e os maiores com o esfagno.

Na vermiculita, o contato das sementes com o substrato é bem maior (FIGLIOLIA et al., 1993); no entanto, em todas as temperaturas testadas, o referido substrato proporcionou baixos valores de germinação e vigor para sementes de Bauhinia divaricata. Em contrapartida, para Maquira sclerophylla (Ducke) C.C. Berg., o substrato vermiculita, juntamente com a temperatura de $30^{\circ} \mathrm{C}$, foram indicados como ótimos para a germinação de suas sementes (MIRANDA \& FERRAZ, 1999).
Os substratos testados nesse estudo influenciaram sensivelmente a germinação e o vigor das sementes de $\boldsymbol{B}$. divaricata, conforme constatado pela análise dos resultados. É provável que, além da capacidade de retenção dos substratos, as características intrínsecas que regulam o fluxo de água das sementes possam ter influenciado os resultados. A variação na disponibilidade de água dos substratos, fator comum nesse tipo de trabalho (PETERSON \& COOPER, 1979), causa freqüentemente prejuízos à germinação das sementes, provocando diferenças entre as médias.

\section{CONCLUSÃO}

A temperatura de $25^{\circ} \mathrm{C}$ é adequada para condução de testes de germinação e vigor (primeira contagem e índice de velocidade de germinação) com sementes de Bauhinia divaricata. O substrato areia, nas três temperaturas $\left(20-30,25\right.$ e $\left.30^{\circ} \mathrm{C}\right)$, foi responsável pelas menores porcentagens de germinação e níveis de vigor das sementes.

\section{REFERÊNCIAS}

ALBRECHT, J.M.F. et al. Influência da temperatura e do tipo de substrato na germinação de sementes de cerejeira. Revista Brasileira de Sementes, Brasília, v.8, n.1, p.49-55, 1986.

ALBUQUERQUE, M.C.F. et al. Influência da temperatura e do substrato na germinação de sementes de saguaraji (Colubrina glandulosa Perk. - Rhamnaceae). Revista Brasileira de Sementes, Brasília, v.20, n.2, p.108-111, 1998.

ALVES, E.U. et al. Germinação de sementes de Mimosa caesalpiniaefolia Benth. em diferentes substratos e temperaturas. Revista Brasileira de Sementes, Brasília, v.24, n.1, p.169178, 2002.

ANDRADE, A.C.S. et al. Germinação de sementes de jenipapo: temperatura, substrato e morfologia do desenvolvimento pósseminal. Pesquisa Agropecuária Brasileira, Brasília, v.35, n.3, p.609-615, 2000.

ANDRADE, A.C.S. et al. Reavaliação do efeito do substrato e da temperatura na germinação de sementes de palmiteiro (Euterpe edulis Mart.). Revista Árvore, Viçosa, v.23, n.3, p.279-283, 1999.

ANDRADE, A.C.S.; PEREIRA, T.S. Efeito do substrato e da temperatura na germinação e no vigor de sementes de cedro Cedrela odorata L. (Meliaceae). Revista Brasileira de Sementes, Brasília, v.16, n.1, p.34-40, 1994.

BEZERRA, A.M.E. et al. Germinação e desenvolvimento de plântulas de melão-de-são-caetano em diferentes ambientes e substratos. Revista Ciência Agronômica, Fortaleza, v.33, n.1, p.39-44, 2002.

Ciência Rural, v.38, n.4, jul, 2008. 
BILIA, D.A.C. et al. Germinação de diásporos de canela-preta (Ocotea corymbosa (Meissn.) Mez - Lauraceae) em função da temperatura, do substrato e da dormência. Revista Brasileira de Sementes, Brasília, v.20, n.1, p.189-194, 1998.

BORGES, E.E.L.; RENA, A.B. Germinação de sementes. In: AGUIAR, I.B. et al. (Eds.). Sementes florestais tropicais. Brasília: ABRATES, 1993. p.83-135.

BRASIL. Ministério da Agricultura e Reforma Agrária. Regras para análise de sementes. Brasília: SNDA/DNDV/CLAV, 1992. 365p.

CARVALHO, N.M.; NAKAGAWA, J. Sementes: ciência, tecnologia e produção. 4.ed. Jaboticabal: FUNEP, 2000. 588p.

CAVALCANTE, A.M.B.; PEREZ, S.C.J.G.A. Efeitos da temperatura sobre a germinação de sementes de Leucaena leucocephala (Lam.) de Wit. Revista Brasileira de Sementes, Brasília, v.17, n.1, p.1-8, 1995.

CETNARSKI FILHO, R.; NOGUEIRA, A.C. Influência da temperatura na germinação de diásporos de Ocotea odorifera (Vellozo) Rohwer (canela-sassafrás). Ciência Florestal, Santa Maria, v.15, n.2, p.191-198, 2005.

COPELAND, L.O.; MCDONALD, M.B. Principle of seed science and technology. New York: Chapman \& Hall, 1995. 409p.

FIGLIOLIA, M.B. et al. Análise de sementes. In: AGUIAR, I.B. et al. (Eds.). Sementes florestais tropicais. Brasília: ABRATES, 1993. p.137-174.

GARCIA, L.C. Influência da temperatura na germinação de sementes e no vigor de plântulas de cupuaçuzeiro (Theobroma grandiflorum (Willd. Ex-Spreng) Schum). Pesquisa Agropecuária Brasileira, Brasília, v.29, n.7, p.1145-1150, 1994.

IOSSI, E. et al. Efeitos de substratos e temperaturas na germinação de sementes de tamareira-anã (Phoenix roebelenii O’Brien). Revista Brasileira de Sementes, Pelotas, v.25, n.2, p.63-69, 2003.

LIMA, D.; GARCIA, L.C. Avaliação de métodos para o teste de germinação em sementes de Acacia mangium Willd. Revista Brasileira de Sementes, Brasília, v.18, n.2, p.180-185, 1996.

LOPES, J.C. et al. Germinação de sementes de calabura (Muntingia calabura L.). Revista Brasileira de Sementes, Brasília, v.24, n.1, p.59-66, 2002.

LORENZI, H. Árvores brasileiras: manual de identificação e cultivo de plantas arbóreas nativas do Brasil. Nova Odessa: Plantarum, 2002. 368p.

MACHADO, C.F. et al. Metodologia para a condução do teste de germinação em sementes de ipê-amarelo (Tabebuia serratifolia (Vahl) Nicholson). Revista Cerne, Lavras, v.8, n.2, p.18-27, 2002.

MAGUIRE, J.D. Speed of germination aid in selection and evaluation for seedling emergence and vigour. Crop Science, Madison, v.2, n.2, p.176-177, 1962.
MARCOS FILHO, J. Germinação de sementes. In: CÍCERO, S.M. et al. Atualização em produção de sementes. Piracicaba: Fundação Cargill, 1986. 11-39p.

MIRANDA, P.R.M.; FERRAZ, I.D.K. Efeito da temperatura na germinação de sementes e morfologia da plântula de Maquira sclerophylla (Ducke) C.C. Berg. Revista Brasileira de Botânica, São Paulo, v.22, n.2, p.303-307, 1999.

NAKAGAWA, J. Testes de vigor baseados no desempenho das plântulas. In: KRZYZANOWSKI, F.C. et al. (Eds.). Vigor de sementes: conceitos e testes. Londrina: ABRATES, 1999. p.2.1-2.21.

PACHECO, M.V. et al. Efeito de temperaturas e substratos na germinação de sementes de Myracrodruon urundeuva Fr. All. (Anacardiaceae). Revista Árvore, Viçosa, v.30, n.3, p.359367, 2006.

PEREZ, S.C.J.G.A. et al. Influência do armazenamento, substrato, envelhecimento precoce e profundidade de semeadura na germinação de canafístula. Bragantia, Campinas, v.58, n.1, p.57-68, 1999.

PETERSON, J.R.; COOPER, P.G. Some considerations of water in the germination test. Seed Science and Technology, Zurich, v.7, n.3, p.329-340, 1979.

PIÑA-RODRIGUES, F.C.M.; VIEIRA, J.D. Teste de germinação. In: PIÑA-RODRIGUES, F.C.M. (ed.). Manual de análise de sementes florestais. Campinas: Fundação Cargill, 1988. p.70-90.

PROBERT, R.J. The role of temperature in germination ecophysiology. In: FENNER, M. Seeds: the ecology of regeneration in plant communities. Wallingford: CABI, 1992. p.285-325.

RAMOS, M.B.P.; VARELA, V.P. Efeito da temperatura e do substrato sobre a germinação de sementes de visgueiro do igapó (Parkia discolor Benth.) Leguminosae, Mimosoideae. Revista de Ciências Agrárias, Belém, v.39, p.135-143, 2003.

SANTOS, D.S.B. et al. Efeito do substrato e profundidade de semeadura na emergência e desenvolvimento de plântulas de sabiá. Revista Brasileira de Sementes, Brasília, v.16, n.1, p.50-53, 1994.

SILVA, B.M.S. et al. Germinação de sementes e emergência de plântulas de Oenocarpus minor Mart. (Arecaceae). Revista Brasileira de Fruticultura, Jaboticabal, v.28, n.2, p.289292, 2006.

SILVA, L.M.M.; AGUIAR, I.B. Efeito dos substratos e temperaturas na germinação de sementes de Cnidosculus phyllacanthus Pax \& K. Hoffman (faveleira). Revista Brasileira de Sementes, v.26, n.1, p.9-14, 2004.

VARELA, V.P. et al. Influência da temperatura e do substrato na germinação de sementes de itaubarana (Acosmium nitens (Vog.) Yakovlev) - Leguminosae, Caesalpinoideae. Acta Amazonica, Manaus, v.35, n.1, p.35-39, 2005. 